\title{
Potential Energy Surface (PES) scan of gas-phase L-proline
}

\author{
Anouar EI Guerdaoui ${ }^{*}$, Yassine EI Kahoui, Malika Bourjila, Rachida Tijar, \\ Abderrahman El Gridani \\ Laboratory of Physical Chemistry, Department of Chemistry, Faculty of Science, \\ Ibn Zohr University, Agadir, Morocco \\ *E-mail address: anouarelguerdaoui@gmail.com
}

\begin{abstract}
We performed here a systematic ab initio calculations on neutral gas-phase L-proline. A total of 8 local minima were located by geometry optimization of the trial structures using density functional theory (DFT) with B3LYP three parameter hybrid potential coupled with the $6-31 \mathrm{G}) \mathrm{d}$ ( basis set. The absolute minimum obtained will be subject to a rigid potential energy surface (PES) scan by rotating its carboxylic group using the same method with more accurate basis set B3LYP/6-311++G(d,p), to get a deeper idea about its conformational stability. The main aim of the present work was the study of the rigidity of the L-proline structure and the puckering of its pyrrolidine ring.
\end{abstract}

Keywords: ab initio calculations; L-proline; density functional theory; potential energy surface

\section{INTRODUCTION}

Amino acide present a great challenge for computational methods in quantum chemistry for different reasons. First, they often contain different types of atoms with different electronic properties, such as $\mathrm{H}, \mathrm{C}, \mathrm{N}, \mathrm{O}, \mathrm{S}$. In fact, the different electronegativities lead to a broad charge transfer inter-and intra-molecular. Second, the biomolecules have a wide variety of types of connections from ionic and covalent bonds and hydrogen bonds to Van Der Waals interactions. Finally, the potential energy surfaces (PES) of these molecular systems are very complex, which may have many local minima very close in energy, often separated by low energy barrier. These minima may be located in very flat PES where wide change of the geometry of the molecule can occur with low energy change regions [1-4].

Proline features the amino group as part of a five-membered ring, differing thus from other amino acids in that its chain is bonded to the backbone nitrogene atom and to the alpha carbon atom (noted $\mathrm{C}_{1}$ See Figure 1). This cyclic structure influences greatly protein architecture. It is unique among amino acids because it features only one hydrogen bound to the amino nitrogen. The pyrrolidine of Pro residue may adopt two distinct down and up puckered conformations [5] that are almost equally favorable [6-11], it prevents rotations about the alpha carbon atom and the nitrogen bond. This reduces greatly the number of conformations available to proline [12].

The structural features of pro and its derivatives have been studied by experimental techniques (X-ray crystallography [13-15], NMR [16], and IR [17,18] spectroscopy) and 
theretical molecular mechanics [15,19], perturbed configuration interaction with localized orbitals (PCILO) [20] and ab initio [19,21-24] calculations.

To further the understanding of the conformational landscape of gaseous L-proline, this work provides a thorough theoretical search using reliable computational techniques at high levels of ab initio electronic-structure theory, usingThe DFT/B3LYP )Becke3-Lee-Yang-Parr functional $[25,26]$ method in the search of Pro conformers as it was known to provide accurate molecular structures and the associated vibrational frequencies and infrared intensities [27-29], with various basis sets, e.g., 6-31G(d) and 6-311++G(d,p).

\section{AB INITIO CALCULATIONS: METHODOLOGY}

A series of 22 trial structures were generated for neutral proline by allowing for all combinations of internal single-bond rotamers, as shown in Figure 1. These possible geometries were submitted to full geometry optimisation using density functional theory (DFT), with 6-31G(d) basis. Excluding major conformers with steric clashes and conformers that converged to the same minimum, a total of 8 possible structures for the neutral L-proline molecule are obtained. All calculations were performed with the GAUSSIAN 09 program package [30].

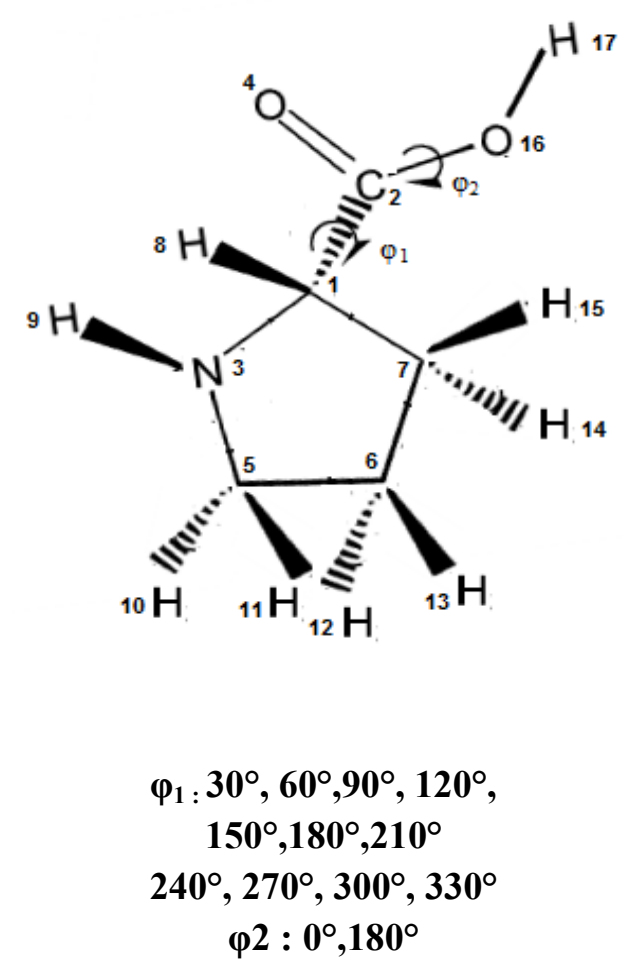

Figure 1. Schematic illustration of the rotational degrees of freedom and Labeling of the atoms of L-proline.

The 2D potential energy surface (PES) of the neutral L-proline (absolute minimum,see Figure 2) was calculated along the dihedral angle of the carboxylic group $\varphi_{2}$ and the torsion $\varphi_{1}$ about the bond $\left(\mathrm{C}_{1}-\mathrm{C}_{2}\right)$ connecting it to the the pyrrolidine ring (see Figure 1). 


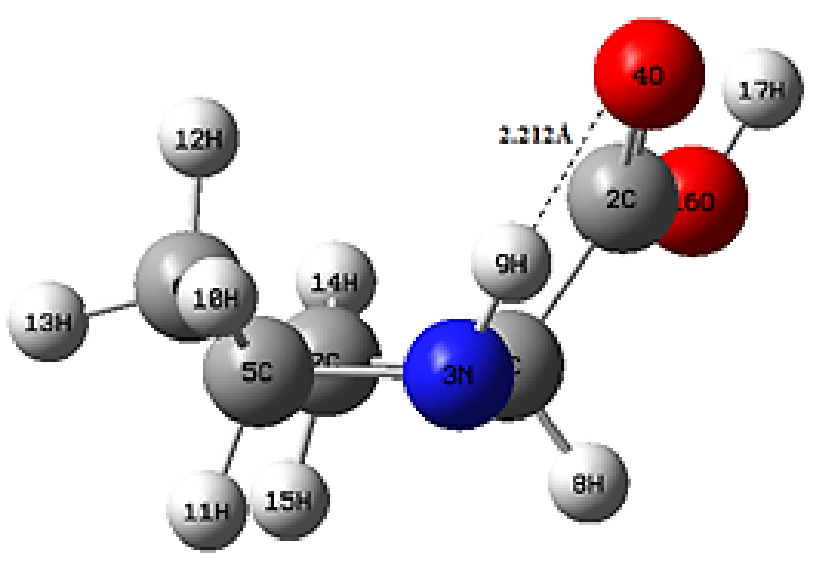

Figure 2. The lowest lying conformer of neutral L-proline located at B3LYP/6-31G(d) level of theory.

\section{RESULTS AND DISCUSSION}

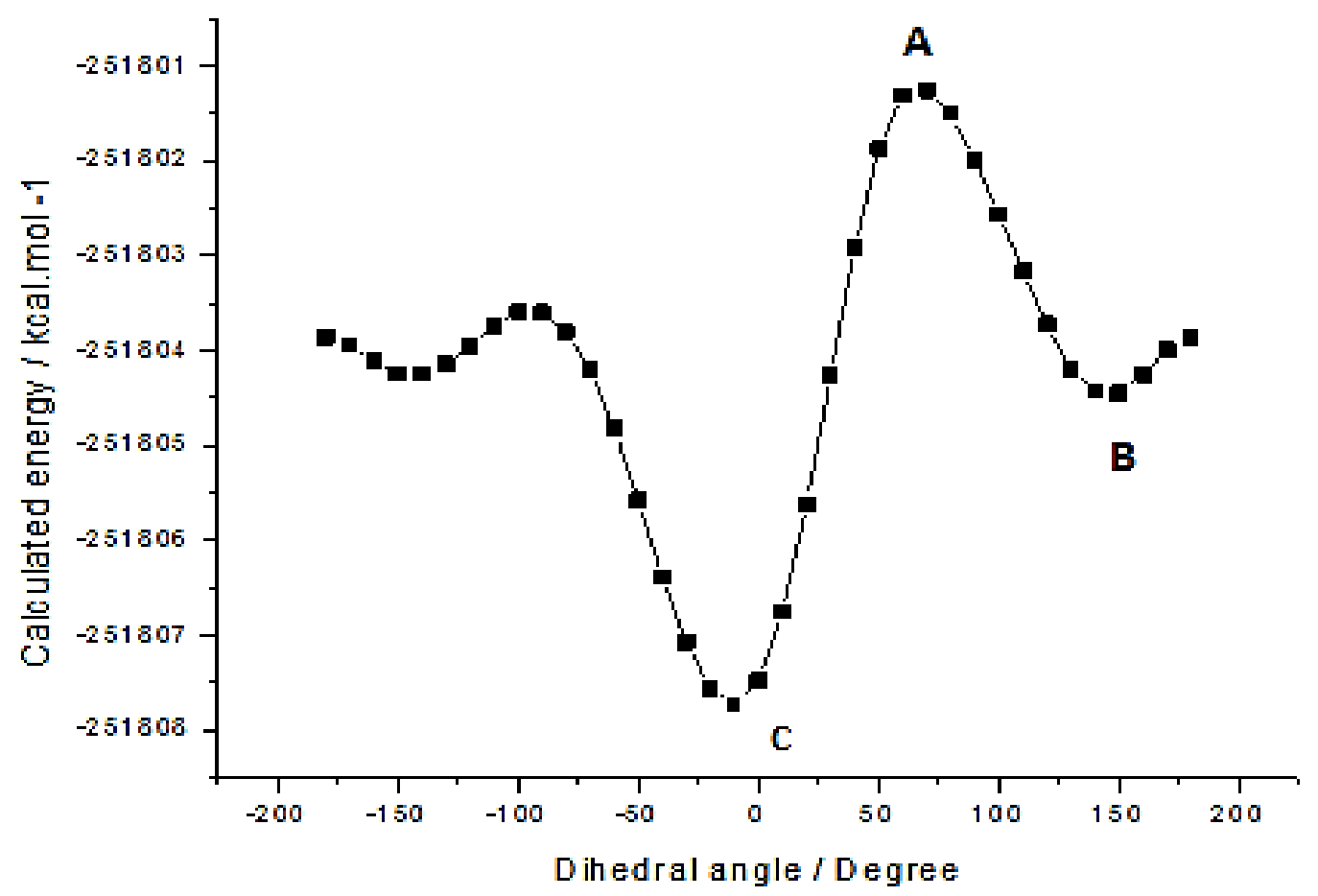

Figure 3. The potential energy surface of L-proline at the B3LYP/6-311++G $(d, p)$ level for $\varphi_{2}=0^{\circ}$.

A rigid potential energy surface scan was performed on the optimized geometry of Lproline (absolute minimum see Figure 2) found previously, with more accurate basis set 6$311++\mathrm{G}(\mathrm{d}, \mathrm{p})[31,32]$, in order to ascertain the structural accuracy and stability using the same method (DFT/B3LYP) by rotating the carboxylic group [ $\varphi_{1}$ : dihedral angle of atom $\mathrm{O}_{4}$ and $\mathrm{N}_{3}$ with respect to the bond $\mathrm{C}_{1}-\mathrm{C}_{2}$, Figure 1] between $-180^{\circ}$ and $+180^{\circ}$ with the increment of 
$10^{\circ}$. Dihedral $\varphi_{2} \quad\left[\varphi_{2}\right.$ : angle of atom $\mathrm{O}_{4}$ and $\mathrm{H}_{17}$ with respect to the bond $\mathrm{C}_{2}-\mathrm{O}_{16}$, Figure 1] has fixed to $0^{\circ}$ and $180^{\circ}$ respectively. The energy curves for pyrrolidine rotation of L-proline are given in Figure 3 and Figure 4 respectively.

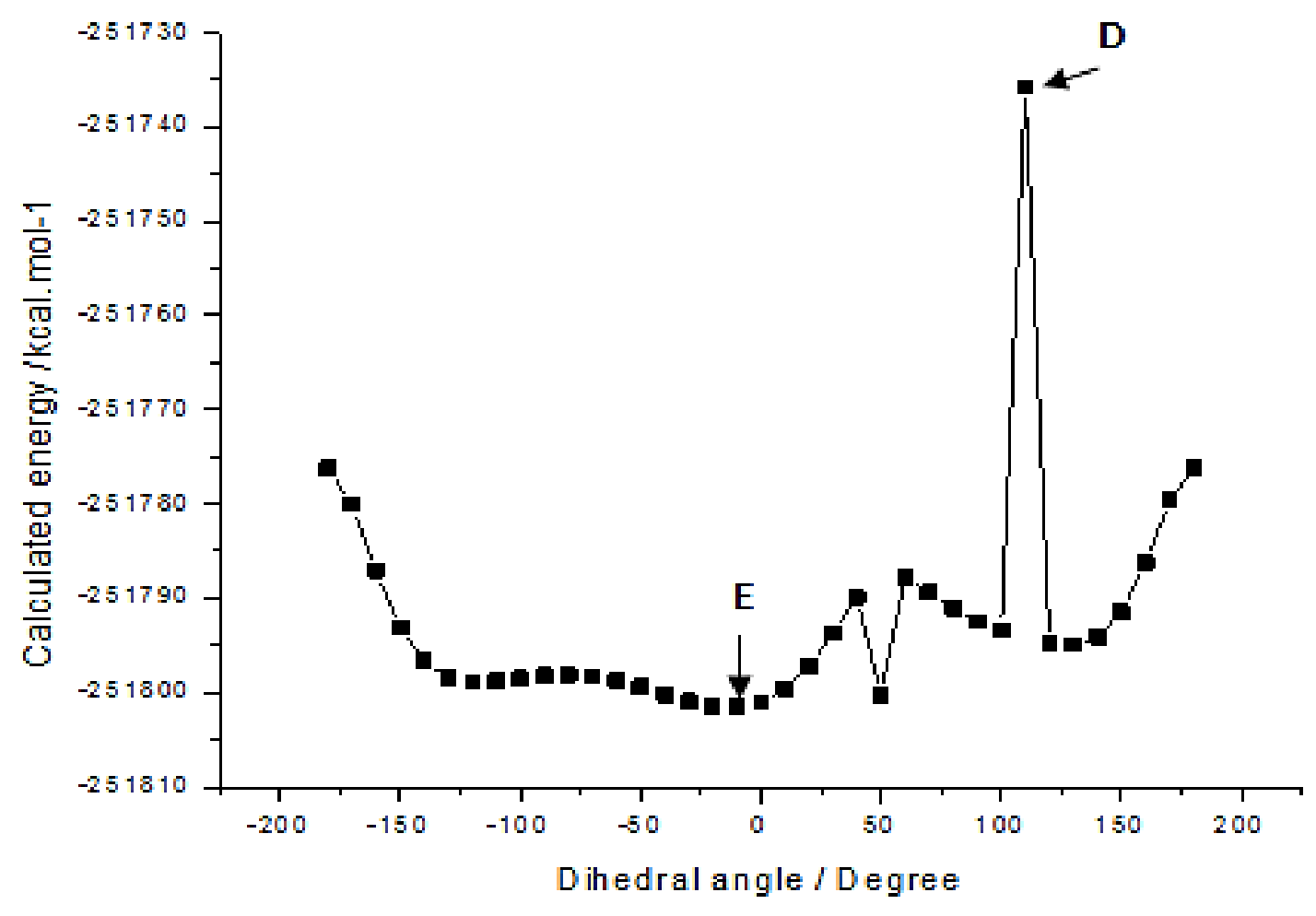

Figure 4. The potential energy surface of L-proline at the B3LYP/6-311++G $(d, p)$ level for $\varphi_{2}=180^{\circ}$

The potential energy curve for carboxylic group rotation of L- proline for $\varphi_{2}=0^{\circ}$ (i.e cis arrangement of $-\mathrm{COOH}$ group) is given in Figure 3. The maximal position in the curve is presented by the highest energy conformer $\mathbf{A}\left(\mathbf{E}_{\mathbf{A}}=-251801,3 \mathrm{kcal} \cdot \mathrm{mol}^{-1}\right)$ with dihedral angle $\varphi_{1}=70^{\circ}$.

Two low energy wells are also identified in the curve Figure 3 and they are presented by conformations $\mathbf{B}$ with dihedral angle $\varphi_{1}=160^{\circ}$ and $\mathbf{C}$ with dihedral angle $\varphi_{1}=-10^{\circ}$, respectively $\left(\mathbf{E}_{\mathbf{B}}=-251804,3 \mathrm{Kcal} \cdot \mathrm{mol}^{-1}\right.$ and $\left.\mathbf{E}_{\mathbf{C}}=-251806,8 \mathrm{kcal} \cdot \mathrm{mol}^{-1}\right)$.

Conformer $\mathbf{A}$ of higher energy, adopts an endo puckering structure of the pyrrolidine ring and up orientation of the imino group $\mathrm{N}_{3}-\mathrm{H}_{9}$, with a weeker hydrogen bond between the oxygen of the carbonyl group $\mathrm{C}_{2}=\mathrm{O}_{4}$ and the hyrogen of the imino group $\mathrm{N}_{3}-\mathrm{H}_{9}$ (using a distance of $2.80 \AA$ as a cutoff for near-atom interactions).

The two low energy conformers $\mathbf{B}$ and $\mathbf{C}$ adopt an endo puckering structure and up orientation of the imino group $\mathrm{N}_{3}-\mathrm{H}_{9}$. They differ only by the dihedral angle $\varphi 2$ and have very similar intramolecular interactions. their separation can be attributed to the interaction between the hydrogen of the imino group N-H and the oxygen of the hydroxyl group which is lower than that of the carbonyl oxygen atom. Energy Barriers of rotation for the $-\mathrm{COOH}$ group $\left(\varphi_{2}=0^{\circ}\right.$, i.e cis arrangement) are 3 and $6.5 \mathrm{kcal} \mathrm{mol}^{-1}$ for $\mathbf{B}$ and $\mathbf{C}$ respectively indicate 
that the rotation of the $-\mathrm{COOH}$ group is relatively much restricted. Structure of highest and lowest energy conformers are given in Figure 5.

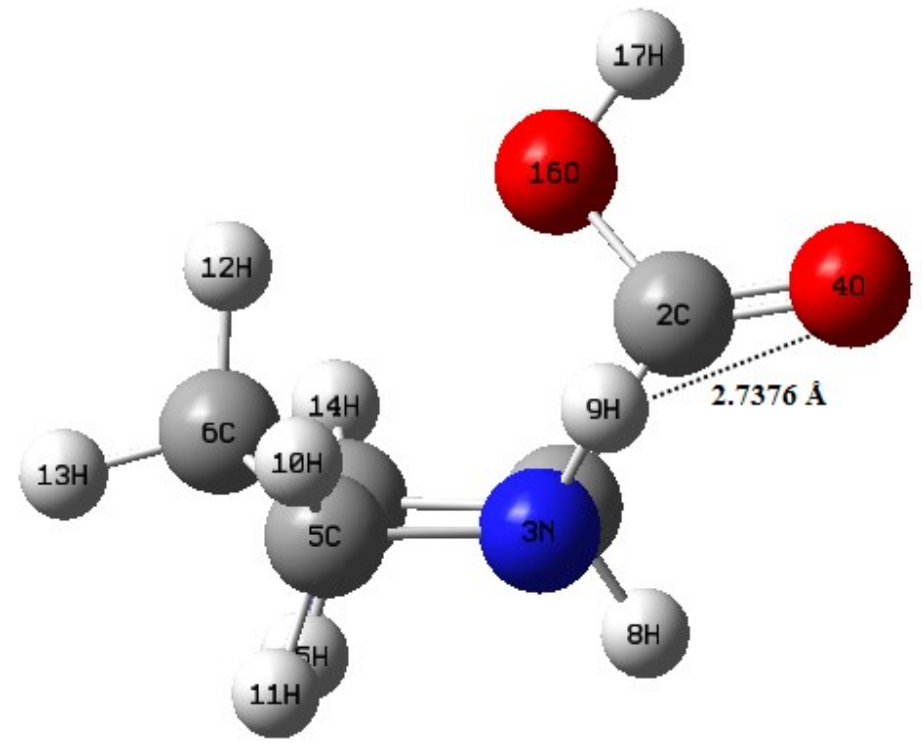

(A)

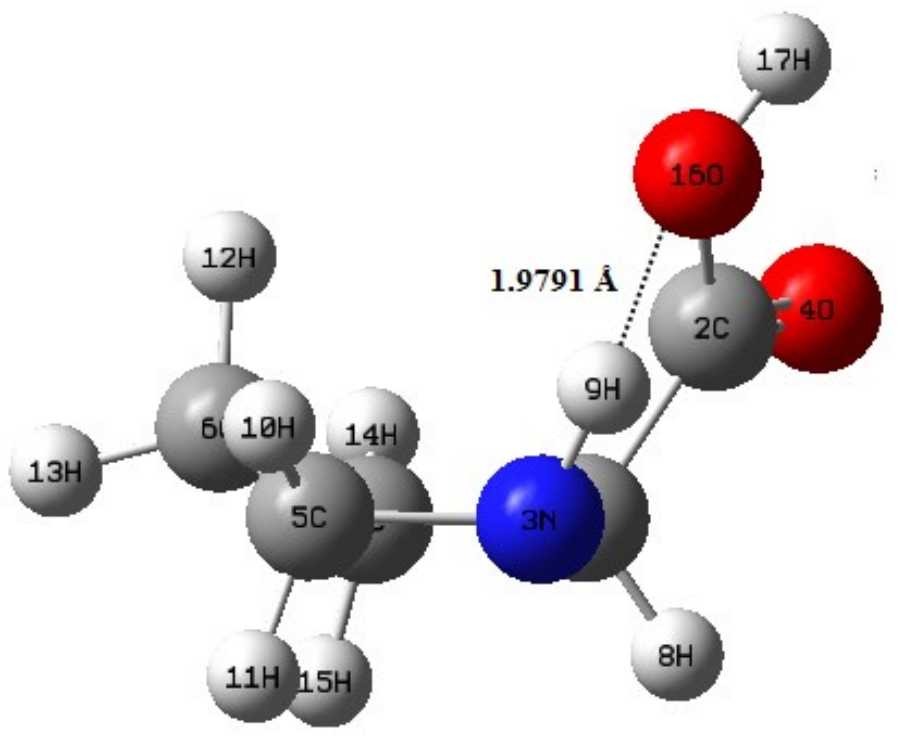

(B) 


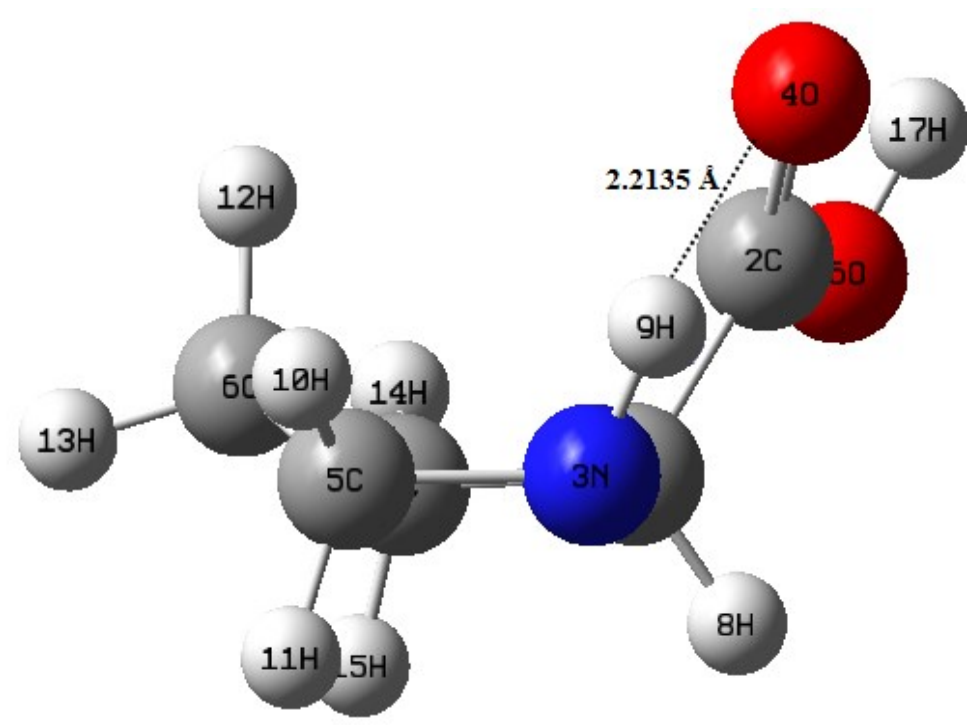

(C)

Figure 5. Highest and lowests energy conformations of L-proline for $\varphi_{2}=0^{\circ}$ (i.e cis arrangement of $\mathrm{COOH}$ group). All the conformations related to Figure 3.

The potential energy curve for carboxylic group rotation of L- proline for $\varphi_{2}=180^{\circ}$ (i.e trans arrangement of $-\mathrm{COOH}$ group) is given in Figure 4. The highest energy conformer of the energy curve is named $\mathbf{D}$ where $\mathbf{E}_{\mathbf{D}}=-251735,9 \mathrm{kcal} \cdot \mathrm{mol}^{-1}$ with dihedral angle $\varphi_{1}=110^{\circ}$ and the lowest energy conformer in the same curve is named $\mathbf{E}$ where $\mathbf{E}_{\mathbf{E}}=-251801,5$ $\mathrm{kcal} \cdot \mathrm{mol}^{-1}$ with dihedral angle $\varphi_{1}=-10^{\circ}$.

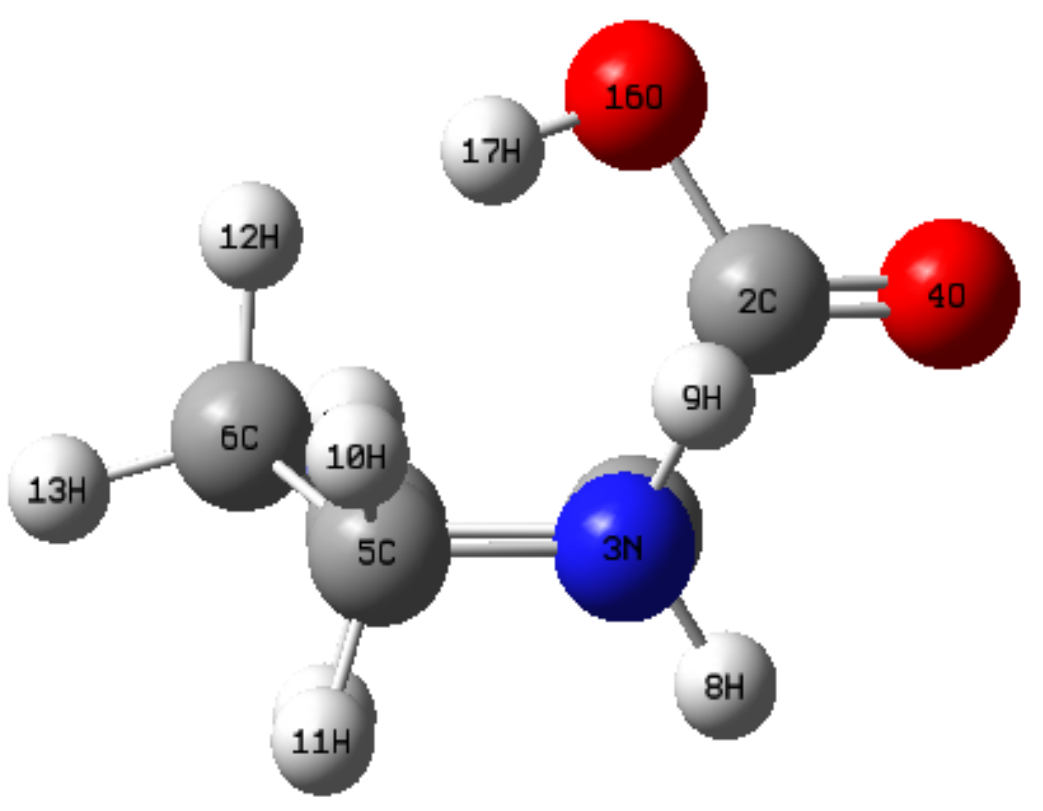

(D) 


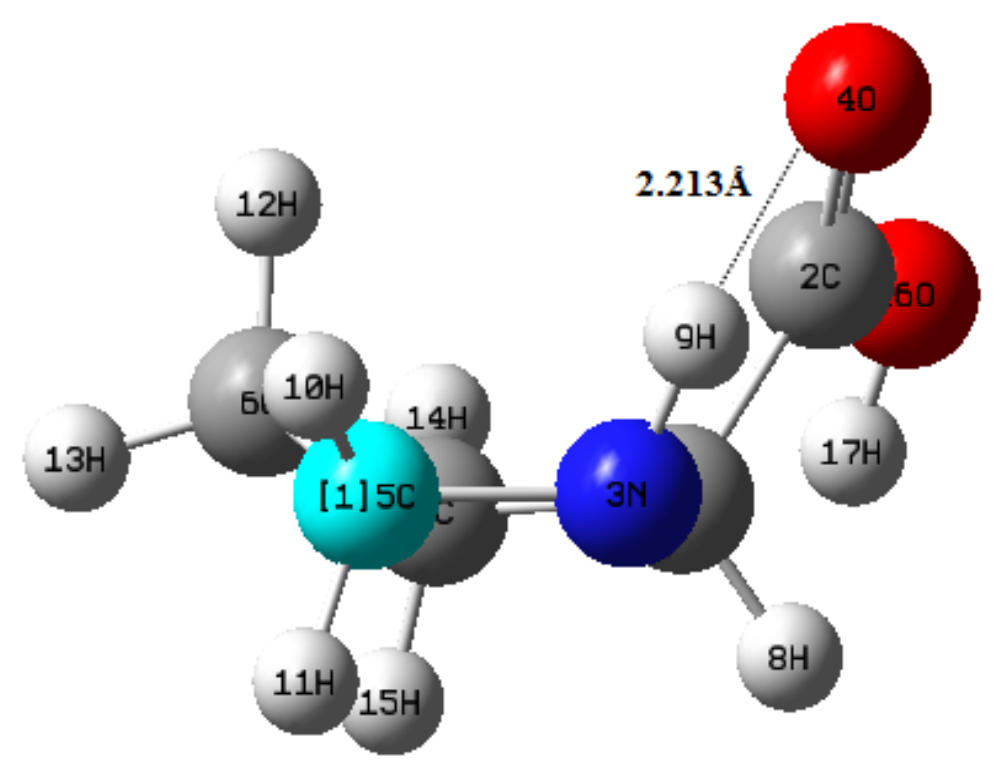

(E)

Figure 6. highest and lowest energy conformations of L-proline for $\varphi_{2}=180^{\circ}$ (i.e trans arrangement of $-\mathrm{COOH}$ group). The two conformations related to Figure 4.

Structures of conformers $\mathbf{D}$ and $\mathbf{E}$ are given in Figure 6. Both $\mathbf{D}$ and $\mathbf{E}$ have an endo puckering structure of the pyrrolidine ring and up orientation of the imino group $\mathrm{N}_{3}-\mathrm{H}_{9}$. The high stability of the lowest conformer $\mathbf{E}$ can be explained by the presence of the hydrogen bond between the hydrogen of the imino group and the oxygen carbonyl $\mathrm{NH}_{9}-{ }^{---} \mathrm{O} O=\mathrm{C}(2.21$ $\AA$ ). The low stability of the conformer $\mathbf{D}$ is obvious, considering the lack of any hydrogen bonding. Barrier of rotation for the $-\mathrm{COOH}$ group $\left(\varphi_{2}=180^{\circ}\right.$, i.e trans arrangement $)$ is of $65.6 \mathrm{kcal} \cdot \mathrm{mol}^{-1}$ for conformer $\mathbf{E}$. This value of energy barrier of rotation is very significant because it can provide information on the conformational preference of the neutral L-proline, a large value indicates that the rotation of the $-\mathrm{COOH}$ group is very much restricted. These results describe the anti-COOH structure be more fit, which is in good agreement with the theoretical results already established [33].

\section{CONCLUSIONS}

The potential energy surface (PES) scan of the neutral gas-phase L-proline was performed using DFT-B3LYP/6-311++G(d,p) level of theory for both cis and trans arrangement of the carboxylic group $-\mathrm{COOH}$. The pyrrolidine ring in proline was calculated to be almost planar at the RHF level with the STO-3G and 6-31G basis sets [34]. while, more elaborate electronic-structure results, especially those employing polarization functions in the basis set [35], show that the ring is considerably puckered in all conformers. In All highests and lowests energy conformers in the etablished energy curves the character of the $\mathrm{N}$ atom is pyramidal, and all these conformers adopt an endo puckering structure of the pyrrolidine ring.

The potential energy scan of L-proline by rotating the tans arrangement $-\mathrm{COOH}$ group shows energy barrier of rotation of $65.6 \mathrm{kcal} \cdot \mathrm{mol}^{-1}$, what it means that the rotation of the trans 
arrangement $-\mathrm{COOH}$ group is very much restricted and therefore a rigid global structure, also this big value of barrier energy suggests rigidityin inprotein's structures by the effect of the interactions that the carboxylic group in the trans form can do with other atoms and therefore this imposes very precise spatial positioning of these proteins.

\section{References}

[1] L. C. Snoek, E. G. Robertson, R. T. Kroemer, J. P. Simons, Chem. Phys. Lett. 321 (2000) 49.

[2] Z. Huang, W. Yu, Z. J. Lin, THEOCHEM . 758 (2006) 195.

[3] (a) K. T. Lee, J. Sung, W. J. Lee, S. K. Kim, Y. D. Park, Chem. Phys. Lett. 368 (2003) 262 ;

(b) Y. Lee, J. Jung, B. Kim, P. Butz, L. C. Snoek, R. T.Kroemer, J. P. Simons, J. Phys. Chem A. 108 (2004) 69.

[4] S. K. Burley, G. A. Petsko, J.Am. Chem. Soc. 108 (1986) 7995.

[5] F. A. Momany, R. F. McGuire, A.W. Burgess, H. A. Scheraga, J. Phys. Chem. 79 (1975) 2361.

[6] D. F. DeTar, N. P. Luthra, J. Am. Chem. Soc. 99 (1977) 1232.

[7] V. Madison, Biopolymers. 6 (1977) 2671

[8] G. Némethy, K. D. Gibson, K. A. Palmer, C. N. Yoon, G. Paterlini, A. Zagari, S. Rumsey, H. A. Scheraga, J. Phys. Chem. 96 (1992) 6472.

[9] Y. K. Kang, J. Phys. Chem. 100 (1996) 11589.

[10] Y. K. Kang, J. S. Jhon, S. J. Han, J. Peptide. Res. 53 (1999) 30.

[11] Y. K. Kang and H.S. Park, J. Mol. Struct. 593 (2002) 55.

[12] A. M. Sapse, Molecular orbital calculations for Amino Acids and Peptide, Birkhäuser, Boston, 2000, p. 63-72.

[13] R. L. Kayushina, B. K. Vainstein, Sov. Phys. Crystallogr. 10 (1966 )698.

[14] R. Balasubramanian, A. V. Lakshminarayanan, M. N. Sabesan, G. Tegoni, K. Venkatesan, G. N. Ramachandran, Int. J. Pept. Protein Res. 3(1971) 25.

[15] D. F. DeTar, N. P. Luthra, J. Am. Chem. Soc. 99 (1977) 1232

[16] C. A. G. Haasnoot, F. A. A. M. De Leeuw, H. P. M. De Leeuw, C. Altona, Biopolymers. 20 (1981) 1211.

[17] I. D. Reva, S. G. Stepanian, A. M. Plokhotnichenko, E. D. Radchenko, G. G. Sheina, Yu. P. Blagoi, J. Mol. Struct. 318 (1994) 1.

[18] A. W. Herlinger, T. V. Long II, J. Am. Chem. Soc. 92 (1970)6481.

[19] M. Ramek, A. M. Kelterer, S. Nikolic, Int. J. Quantum. Chem. 65 (1997) 1033.

[20] D. Cabrol, H. Brock, D. Vasilescu, Int. J. Quantum. Chem. 6 (1979)365. 
[21] A. M. Sapse, L. Mallah-Levy, S. B. Daniels, B. W. Erickson, J. Am. Chem. Soc. 109 (1987) 3526.

[22] A. G. Csaszar, A. Perczel, Progr. Biophys. Mol. Biol. 71 (1999) 243.

[23] P. Tarakeshwar, S. Manogaran, J. Mol. Struct. 365 (1996) 167.

[24] S. G. Stepanian, I. D. Reva, E. D. Radchenko, L. Adamowicz, J. Phys. Chem. A. 105 (2001) 10664.

[25] A. D. Becke, Phys. Rev. B. 38 (1988) 3098.

[26] C. Lee, W. Yang, R. G. Parr. Phys. Rev. B. 37 (1988) 785.

[27] S. G. Stepanian, I. D. Reva, E. D. Radchenko, L. Adamowicz, J. Phys. Chem. A. 102 (1998) 1041.

[28] S.G. Stepanian, I.D. Reva, E.D. Radchenko, L. Adamowicz, J. Phys. Chem. A 102 (1998) 4623.

[29] S. G. Stepanian, I. D. Reva, E. D. Radchenko, L. Adamowicz. J. Phys.Chem. A 103 (1999) 4404.

[30] M. J. Frisch, G. W. Trucks, H. B. Schlegel, G. E. Scuseria, M. A. Robb, J. R. Cheeseman, G. Scalmani, V. Barone, B. Mennucci, G. A. Petersson, H. Nakatsuji, M. Caricato, X. Li, H. P. Hratchian, A. F. Izmaylov, J. Bloino, G. Zheng, J. L. Sonnenberg, M. Hada, M. Ehara, K. Toyota, R. Fu- kuda, J. Hasegawa, M. Ishida, T. Nakajima, Y. Honda, O. Kitao, H. Nakai, T. Vreven, J. A. Montgomery Jr., J. E. Peralta, F. Ogliaro, M. Bearpark, J. J. Heyd, E. Brothers, K. N. Kudin, V. N. Staroverov, R. Kobayashi, J. Normand, K. Raghavachari, A. Rendell, J. C. Burant, S. S. Iyengar, J. Tomasi, M. Cossi, N. Rega, J. M. Millam, M. Klene, J. E. Knox, J. B. Cross, V. Bakken, C. Adamo, J. Jaramillo, R. Gomperts, R. E. Stratmann, O. Yazyev, A. J. Austin, R. Cammi, C. Pomelli, J. W. Ochterski, R. L. Martin, K. Morokuma, V. G. Zakrzewski, G. A. Voth, P. Salvador, J. J. Dannenberg, S. Dapprich, A. D. Daniels, O. Farkas, J. B. Foresman, J. V. Ortiz, J. Cioslowski and D. J. Fox, "Gaussian 09," Revision A.1, Gaussian, Inc., Wallingford, 2009.

[31] P. C. Hariharan, J. A, Theor. Chim. Acta. 28 (1973) 213.

[32] T. Clark, J. Chandrasekhar, G. W. Spitznagel, P.Von Rague Schleyer, J. Comput. Chem. 4 (1983) 294.

[33] T. Marino, N. Russo, E. Tocci, M. Toscano, International Journal of Quantum Chemistry 84 (2001) 2.

[34] A.M. Sapse, L. Mallah-Levy, S. B. Daniels, B. W. Erickson, J. Am. Chem. Soc. 109 (1987) 3526.

[35] M. J. Frisch, J. A. Pople, J. E. Del Bene, J. Phys. Chem. 89 (1985) 3664. 